\title{
REFLEXIONES SOBRE LA DESAPARICIÓN DE LA INFANCIA
}

\section{Resumen}

Si la infancia ha desaparecido o está en vías de desaparecer, las reflexiones y prácticas pedagógicas tendrían que transformarse. El presente artículo retoma algunos estudios en los que la infancia es considerada como una categoría social, histórica, y por tanto, variable en el tiempo y en distintas culturas; de otro lado, señala algunos trabajos que desde la década de los años ochenta han venido planteando la "desaparición" de la infancia y, a propósito de ellos, esboza algunos reflexiones preliminares sobre las implicaciones que tal acontecimiento tendrá para el saber pedagógico, el maestro y la escuela.

Palabras clave: Infancia, desaparición, medios de comunicación, televisión, niño.

\begin{abstract}
If infancy has disappeared or is in roads of disappearing, the reflections and practical pedagogic would have to be transformed. The present work recaptures some studies in those the childhood is considered as a social, historical category, and therefore, variable in the time and in different cultures; the other side, it points out some works that from the decade of years eighty have come outlining the "disappearance" of childhood and, about them, it sketches some preliminary reflections on the implications that such event will have for the pedagogical knowledge went, the teacher and the school.
\end{abstract}

Key words: Infancy, disappearance, mass media, television, infant.

En 1900, la escritora sueca Ellen Key, proclamaba el nuevo siglo como "el siglo del niño". Sobre la base de un profundo optimismo pe-

* Profesor Universidad Pedagógica Nacional - carlosernesto@supercabletv.co dagógico, Key consideraba que una reforma radical de las prácticas de crianza y educación llevaría a un mejoramiento de las cualidades psíquicas de la humanidad, produciendo, de esta manera, un cambio mental general que contribuiría a resolver los problemas sociales y a transformar el mundo. De ahí su insistencia en la protección de la infancia y en la necesidad de transformar la educación infantil en las escuelas y la actitud de los padres frente a la educación de sus hijos. 
Sin lugar a dudas, el lugar que ocupó la infancia en las preocupaciones, reflexiones y acciones durante el siglo pasado en Occidente, ratifica la nominación que hiciese Key de aquel como el siglo del niño, pues ninguna otra sociedad en otro momento ha hablado tanto de la infancia, ha escrito tanto sobre ella ni ha erigido tantas instituciones cuyo encargo es justamente el cuidado y desarrollo infantil. Desde este punto de vista, podríamos decir que la infancia es un acontecimiento relativamente reciente en nuestra cultura. No tiene más de tres siglos de existencia y, sin embargo, nos parece como si la niñez hubiese ocupado siempre el lugar privilegiado que hoy le otorgamos -o queremos otorgarle- en nuestras sociedades. Por ello, quizá nos cueste mucho trabajo imaginarnos que antes de los siglos XVII y XVIII la presencia de la infancia carecía de importancia, o, por lo menos, era considerada tan sólo como un momento, y no precisamente el más importante de la vida humana.

Grandes intelectuales, como San Agustín o Descartes, vieron a la infancia, o como la edad del pecado o como la edad del error. San Agustín, siguiendo las doctrinas bíblicas, se avergonzaba de la niñez, pues la consideraba como la máxima expresión de la naturaleza animal del hombre. Además de ser el fruto del pecado (producto de una relación carnal), la infancia, para este sabio medieval, era la edad de las pasiones, de la exaltación de los instintos animales. Siglos más tarde, en los umbrales de la era de la razón, Descartes veía en la infancia el precio que debía pagar el hombre por obtener el tan preciado entendimiento. La niñez era para este filósofo, lo opuesto a la razón, y por lo tanto, la época del error. En algunas de sus reflexiones filosóficas pensaba cuán feliz sería el hombre si desde su nacimiento tuviese entendimiento, juicio, razón. Pero la naturaleza humana era imperfecta y entonces debíamos pasar tantos años en la oscuridad, en el error, sujetos a los

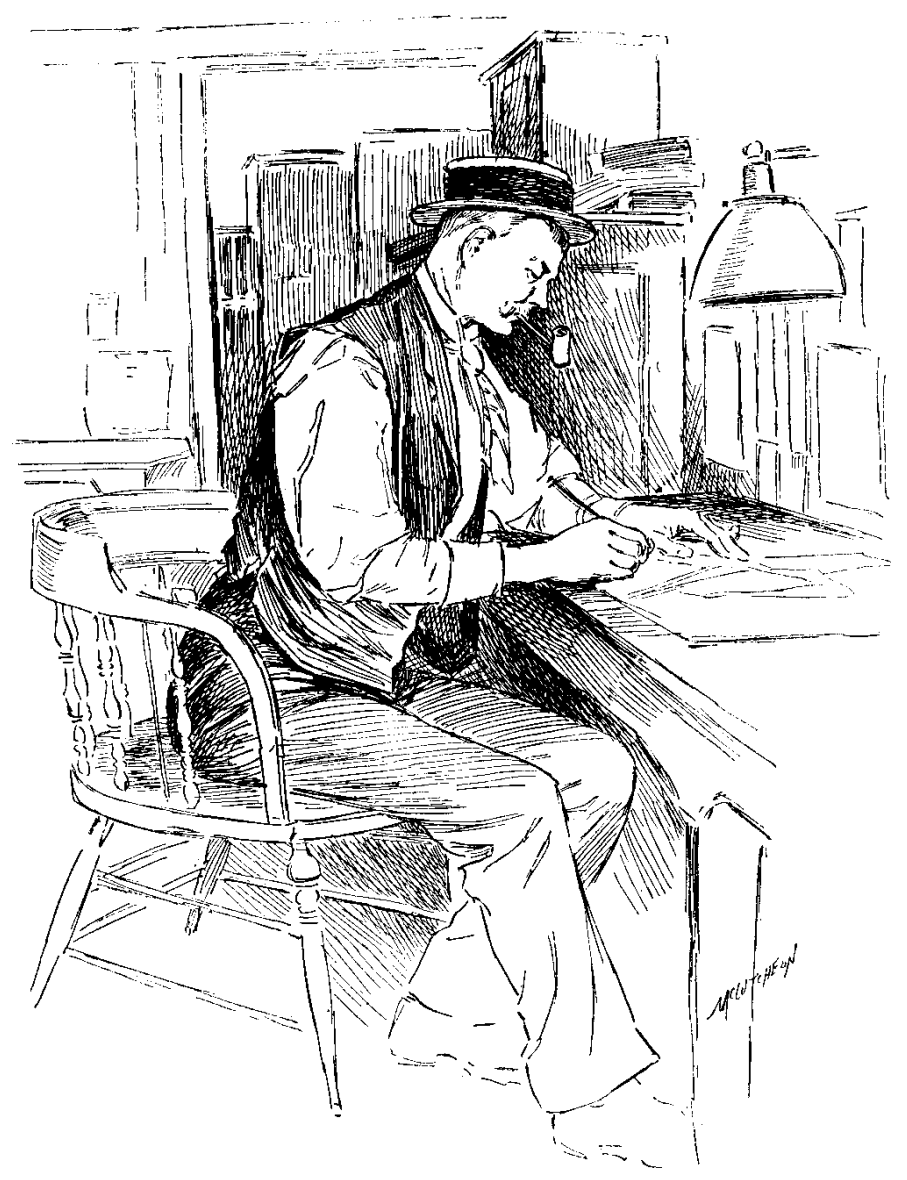

instintos, a los deseos, a las sensaciones, a los prejuicios, antes de llegar, por fin, a disfrutar de ese don que nos llevaba al trono de la creación (Bandinter, 1991).

Se ha mencionado a dos filósofos, a dos pensadores; sin embargo, la imagen negativa de la infancia no fue sólo asunto de intelectuales. Durante siglos, las mujeres europeas manifestaron una total indiferencia frente al fruto de su vientre. En algunos períodos de la historia, se negaron a dar pecho a sus hijos y para ello recurrieron a las nodrizas, quienes a su vez, abandonaban a sus vástagos para vender su leche. En otros momentos, la muerte de sus hijos llegó a ser un hecho tan común, que muy seguramente se sorprenderían si pudiesen observar el profundo dolor con el que una madre moderna entierra a cualquiera de sus hijos infantes (Bandinter, 1991).
En su libro sobre la infancia y la vida familiar durante la Edad Media, el historiador francés, Phillipe Ariès, nos muestra la indiferencia de la sociedad medieval ante la infancia: no existía un sentimiento particular que se reflejase en las actitudes frente a la muerte, en la distribución de los espacios sociales, en los juegos, en los hábitos de crianza, etc. Según este autor, antes del siglo XVII era común enterrar a los niños en el patio de las casas, como se hacía con cualquier animal doméstico; la presencia de niños en espacios propios de los adultos, como las tabernas, o la ausencia de juegos específicamente infantiles, o incluso, la ausencia de una indumentaria particular para la infancia, de un vestido que diferenciara u otorgara una especificidad al niño o niña, son muestras evidentes de la inexistencia, para esa sociedad, de algo parecido a lo que hoy con- 
sideramos como la niñez. Sólo, hacia el siglo XVIII, la infancia ocuparía por primera vez un sitio privilegiado en la sociedad occidental; sólo hasta entonces, la humanidad comienza a dar muestras de una particular sensibilidad y preocupación por aquella etapa tan frágil de la vida humana.

La infancia, es pues, un acontecimiento relativamente reciente. No un descubrimiento tardío, sino más bien una invención. Una invención cuya aceptación social tuvo que vencer muchos obstáculos, tuvo que pasar por una imposición, que, según nos relata la escritora Elisabeth Badinter (1991), implicó por lo menos tres estrategias diferentes: de una parte, la puesta en evidencia, por parte de ciertos intelectuales, del valor económico de la niñez. Según aquellas novedosas ideas que los fisiócratas de los siglos XVII y XVIII divulgaron, la infancia representaba la mayor riqueza de cualquier nación, pues llegaría a constituir la fuerza trabajadora y productiva de toda república. Así, pues, se dieron a la tarea de elaborar propuestas, como la reforma de los hospicios e incluso sugirieron la alimentación con leche de animales para su preservación. Por otra parte, fue necesario convencer a las madres europeas de la necesidad de amamantar a sus hijos. En esta estrategia los médicos jugaron un papel central; para lograr sus propósitos, utilizaron un doble mecanismo: la seducción y las amenazas. La literatura médica del siglo XVIII en Europa da cuenta de cómo los médicos intentaron convencer a las madres de las bondades de dar pecho a sus hijos. Serían más bellas, más amadas, más felices, y desde luego, más sanas. Por el contrario, si continuaban negándose a ello, sufrirían el reclamo de sus hijos e incluso podrían llegar a la muerte por acumulación y degradación de exceso de leche en sus cuerpos. Una última táctica a la que los nuevos intelectuales ilustrados apelaron para la protección de la infancia fue la consolidación del matrimonio, y en par- ticular, del amor como eje de la relación marital. La familia burguesa, el hogar moderno burgués, aparece allí como fundamento del nuevo orden social, pues sólo un hogar, una familia, podría preservar el tesoro infantil, las tiernas plantas infantiles.

\section{Siglo XX: el siglo de la niñez}

Tanto en los discursos educativos, médicos e higiénicos como en los políticos y jurídicos de comienzos del siglo XX, la niñez empezó a ocupar un lugar destacado. A las voces del movimiento de educación nueva y de la pedagogía activa, se sumaron las de gobernantes, políticos y diplomáticos, quienes, desde los nuevos escenarios políticos de discusión mundial, abogaron por la defensa de la niñez del mundo. Congresos mundiales, conferencias regionales (panamericanas), ligas nacionales se crearon y comenzaron a funcionar a lo largo de la primera mitad del siglo XX: desde el Primer Congreso Internacional de la Protección de la Infancia, realizado en Bruselas en 1913, hasta la Declaración de los Derechos del Niño, en 1959, el mundo occidental conoció la más grande campaña por la protección de aquella etapa de la vida durante siglos ignorada, desconocida, abandonada.

El carácter de estas primeras acciones fue básicamente asistencial

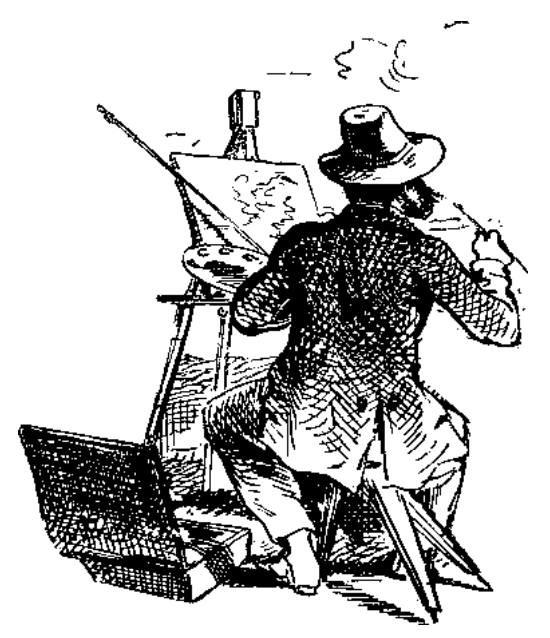

y se ejercían a través de diversas organizaciones de beneficencia, como las gotas de leche, las escuelas, las ligas de protección de la infancia y de asociaciones profesionales, como sociedades de pediatría. Esta fue la perspectiva más relevante hasta la promulgación de la Declaración de los Derechos del Niño en 1959, cuando la concepción sobre la infancia se transforma. Desde ese año y hasta 1989, la ONU y sus órganos asociados fueron complejizando la mirada sobre la niñez, dando inicio a una perspectiva fundamentada en la noción jurídica de "derechos del niño".

\section{La infancia como población vulnerable: la perspectiva asistencial}

El siglo XX caracterizó a la infancia como uno de los grupos poblacionales más altamente vulnerables debido al estado de indefensión característica de su edad. Desde los primeros años del siglo pasado, diversos Estados manifestaron una significativa preocupación por generar mecanismos de asistencia y apoyo a la niñez. Así se expresa en el Primer Congreso Internacional de la Protección de la Infancia en Bruselas (1913) en la Declaración de Ginebra (1924) y en la Declaración universal de los Derechos del Niño.

En 1913, los temas centrales fueron la atención y detección de niños anormales, la higiene de la infancia, el alcoholismo, la mortalidad infantil, la libertad vigilada y tutela de niños naturales, la educación de las madres y la vigilancia sobre parteras y nodrizas (Saenz, Saldarriaga y Ospina, 1997:186). Para 1924 (Declaración de Ginebra) esta preocupación se convirtió en un compromiso moral de la humanidad para dar al niño lo mejor por encima de consideraciones de raza, nacionalidad o creencia. Aparecían como compromisos urgentes ante los niños: posibilitar su desarrollo normal tanto material como espiritual, proveerlos de alimento, cura y atención y contribuir para el socorro, la ayuda y la protección de deficientes, 
desadaptados, huérfanos, abandonados o propensos a situaciones de explotación. También se contempló que "el niño debe ser educado inculcándole el sentido del deber que tiene de poner sus mejores cualidades al servicio del prójimo".

\section{La infancia: sujeto de derechos ${ }^{\star}$}

Si la mirada asistencialista de la primera mitad del siglo XX consideraba la niñez como objeto de atenciones y protección, la nueva perspectiva transforma al niño en sujeto de derechos y deberes. La Declaración Universal de los Derechos del Niño de 1959, retoma los presupuestos sobre infancia expuestos en la convención de Ginebra, y señala que los niños debían estar cobijados por una protección especial garantizada por la ley, en la cual se contemplaran la libertad, la dignidad, las oportunidades y la prestación de los servicios. Así mismo, se consideraron como derechos de los niños: un nombre y una nacionalidad; el desarrollo físico, mental, moral, espiritual y social saludable y normal, la seguridad social (salud, alimentación, vivienda, recreo y servicios médicos adecuados); el desarrollo de su personalidad, mediante el amor y la comprensión de los padres, siempre que fuera posible; la educación gratuita y obligatoria, por lo menos en las etapas elementales, favoreciendo en el niño su cultura, aptitud, juicio individual y sentido de responsabilidad moral y social; el disfrute pleno de juegos y actividades recreativas orientadas hacia los fines educativos.

Uno de los aspectos inéditos de esta perspectiva tiene que ver con la delimitación de una edad mínima para vincularse al mundo laboral. Niños y niñas de siglos anteriores habían trabajado desde corta edad, pero ahora se buscaba preservar la edad infantil para la educación. De esta

\footnotetext{
* Apartado elaborado sobre la base de un trabajo inédito de la profesora Sandra Patricia Rodríguez acerca de la Educación Infantil en Iberoamérica.
}

manera, las acciones propuestas en la Declaración de 1959, no sólo apuntaron a resolver problemáticas concretas, como en 1913 y 1924, sino que, además, se pretendió generar acciones para superar las situaciones adversas y definir políticas que permitieran ampliar las oportunidades de desarrollo y crecimiento de la población infantil.

Entre la Declaración de 1959 y la Convención de 1989, la ONU -en tanto organismo multinacional-, manifestó su preocupación por la niñez en la Declaración Universal de Derechos Humanos, en el Pacto Internacional de Derechos Civiles y Políticos (art. 23 y 24), en el Pacto Internacional de Derechos Económicos, Sociales y Culturales (art. 10) y en los Convenios constitutivos de los organismos especializados y de las organizaciones internacionales que se interesan en el bienestar del niño. Bajo la consideración de que "el niño, por su falta de madurez física y mental, necesita protección y cuidado especiales, incluso la debida protección legal, tanto antes como después del nacimiento" se dispusieron en el ámbito internacional las siguientes medidas que reglamentaron el cuidado, la protección y la atención dirigida a la niñez: Resolución 3318 (XXIX) de la Asamblea General (14 de dic. 1975 sobre la protección de la mujer y el niño en estados de emergencia o de conflicto armado); Resolución 40/33 de la Asamblea General (29 de nov. 1985 en Beijing sobre la normatividad mínima de la ONU para la administración de justicia de menores) y la Resolución 41/ 85 de la Asamblea General (3 de dic. 1986 sobre los principios sociales y jurídicos relativos a la protección y el bienestar de los niños que contemplaron la adopción y colocación de niños en hogares de guarda nacional e internacional).

En 1990, se llevó a cabo la Primera Cumbre Mundial a favor de la Infancia con el fin de proyectar un plan de acción que permitiera desplegar los derechos del niño en políticas, programas y proyectos sociales. La

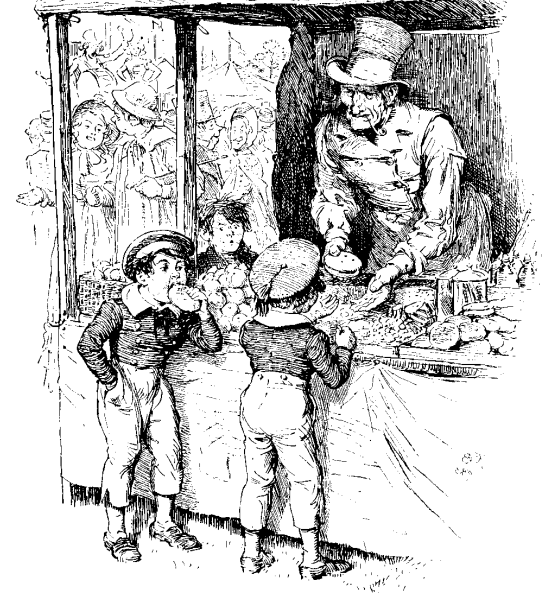

atención a la infancia a propósito de las siete metas propuestas en la Cumbre $^{1}$ y de los lineamientos de la Convención, evidencia una perspectiva integral en la cual se conjugan las acciones que garantizan la salud, la educación, el desarrollo en todas sus dimensiones, el bienestar y la seguridad social. Esta mirada sobre la niñez ha posibilitado que en el último decenio, UNICEF y diversas organizaciones preocupadas por la defensa de la infancia, hayan liderado campañas masivas en contra de las minas terrestres, del empleo de los niños como soldados, de la explotación sexual y otras formas de violencia y hayan juntado esfuerzos encaminados a estudiar e inter-

\footnotetext{
${ }^{1}$ Las siete metas trazadas en el plan de Acción propuesto por la Cumbre fueron: 1) Reducir, con respecto a 1990, la tasa de mortalidad de los niños menores de 5 años en una tercera parte o a un nivel de 70 por 1000 nacidos vivos, si ello representa una mayor reducción. 2) Reducir la tasa de mortalidad materna en un $50 \%$ con respecto al nivel de 1990. 3) reducir la tasa de malnutrición grave y moderada entre los niños menores de 5 años en un $50 \%$ con respecto al nivel de 1990 . 4) Dar acceso a todos al agua apta para el consumo y los servicios sanitarios de eliminación de excrementos. 5) Lograr que por lo menos el $80 \%$ de los niños en edad de asistir a la escuela primaria tenga acceso a la educación básica y termine la enseñanza primaria. 6) Reducir la tasa de analfabetismo de los adultos a por lo menos la mitad del nivel registrado en 1990 (cada país determina el grupo de edades correspondientes), otorgando particular importancia a la alfabetización de las mujeres. 7) Dar protección a los niños en circunstancias especialmente difíciles, sobre todo en situaciones de conflictos armados.
} 
venir la pobreza, la desigualdad, el VIH/SIDA y el trabajo infantil.

Este marco es el que ha guiado la política internacional, los acuerdos regionales, las cumbres de jefes de estado y las conferencias y declaraciones mundiales, tal como se muestra en los siguientes documentos: Declaración Mundial sobre Educación para todos y Marco de acción para satisfacer las Necesidades Básicas de Aprendizaje (Jomtien, Tailandia, marzo de 1990), documento producto de una consulta realizada después de la aprobación de la Convención sobre los Derechos del Niño, en donde 155 Estados y 350 organismos revisaron las necesidades educativas básicas con énfasis en la niñez. En septiembre del mismo año se elaboró la Declaración Mundial sobre la Supervivencia, la Protección y el Desarrollo del Niño, documento en la cual se analizaron las problemáticas de la infancia en la región en torno a la salud del niño, la condición de la mujer y la familia, el analfabetismo y las oportunidades de educación, la protección del niño en circunstancias especiales de conflicto armado, migraciones o extrema pobreza. Un aspecto novedoso en esta declaración fue la promoción de la escolarización de la niña y la mujer con el fin de cumplir con la meta de equidad propuesta por los organismos internacionales.

En Abril de 1991 se celebró la XXII Reunión Ordinaria del Consejo Interamericano para la Educación, la Ciencia y la Cultura de la OEA (CIECC) en la cual los Ministros de Educación de la Región reunidos en Washington, D.C. aprobaron la Resolución 811/91 sobre Proyectos prioritarios en Defensa y Protección de los Niños y Jóvenes en Riesgo y recomendó que los países fortalecieran los Programas de atención integral para niños desde el nacimiento hasta el ingreso a la educación primaria. Entre 1991 y 1996 las Asambleas Generales de la O.E.A, vigilaron el cumplimiento y seguimiento de los acuerdos internacio- nales y acuñaron un nuevo concepto para la política internacional "Atención Integral al Niño Menor de Seis Años a través de Experiencias Formales y No Formales de Educación Inicial y Preescolar" para lograr el principio de equidad.

Entre 1993-1998 los Simposios Internacionales proponen líneas de acción en torno a la Atención integral y pertinencia cultural (Chile 1993), la Participación de los padres de familia y comunidad (Perú 1994), Infancia y Pobreza (Costa Rica 1995), Investigación y evaluación (Brasil 1996), Escenarios culturales, diversidad, equidad y calidad (México 1998). En estos espacios se han ratificado los acuerdos a los que han llegado los Estados participantes en las convenciones y declaraciones celebradas en la región y han definido políticas para el cumplimiento de dichos acuerdos. Próximamente se darán cita los jefes de estado y organismos internacionales con la invitación especial de los niños y jóvenes en la "Sesión Especial a favor de la Infancia", para evaluar y proponer acciones que mejoren los efectos que hasta ahora ha tenido la política promulgada en el último decenio entorno a la infancia².

\footnotetext{
2 A partir del Movimiento a favor de la Infancia promovido por Nelson Mandela ganador del Premio Nobel de la Paz- y Graça Machel -especialista de las Naciones Unidas en cuestiones relativas a los niños en los conflictos armados- se organizó "La Sesión Especial en favor de la Infancia" como un encuentro sin precedentes de la Asamblea General de las Naciones Unidas, dedicada a los niños y adolescentes del mundo. Varios jefes de Estado y de gobierno, ONG, defensores de los derechos de los niños, y los propios niños y niñas, se darían cita en septiembre de 2001 en Nueva York (se aplazó por los hechos del 11 de septiembre) para participar en esta reunión. De la Sesión especial se esperaba un programa mundial que establecía metas y un plan de acción con miras a obtener tres resultados fundamentales: que los niños puedan iniciar sus vidas en las mejores condiciones, que todos los niños puedan recibir una educación básica de buena calidad y que todos los niños y especialmente los adolescentes, puedan participar de manera significativa en la vida de sus comunidades. Se convocaron los líderes de los gobiernos, la sociedad civil y el sector priva-
}

Este conjunto amplio de documentos rubricados a nivel mundial, permiten observar la mirada que desde el concepto de "derechos de la infancia" se ha venido construyendo en la última década. Dentro de esta mirada vale la pena señalar la "aparición" de la niña en el ámbito de la política internacional, pues aunque había sido objeto de análisis desde los años setenta en relación con la idea de equidad y acceso a servicios, durante los últimos diez años se multiplican los estudios en los cuales se analiza la situación de la niña en diferentes ámbitos.

Sin embargo, el auge de los nuevos discursos y la nueva perspectiva de los derechos del niño y la niña, no ha significado el abandono de la concepción asistencialista. Ésta se mantiene a pesar de los intentos de los distintos países iberoamericanos por fortalecer programas integrales de atención, promovidos para su ejecución conjunta con la familia y la comunidad. De otra parte, y siguiendo algunos análisis recientes, la concepción de la infancia como sujeto de derechos ha venido contribuyendo, paradójicamente, a su "desaparición". Como diría Corea, "hoy ya no se trata de tutelar a la infancia sino de velar por que sus derechos se respeten" (COREA, 1999: 127), o dicho de otra manera, del enunciado moderno "la infancia debe ser protegida" -en tanto es frágil, vulnerable, en proceso de ser-, se pasa al nuevo enunciado "los derechos del niño deben ser protegidos" y los derechos infantiles (en particular la posibilidad de elección y decisión sobre aspectos le atañen) llevan a concebir un sujeto muy distinto del promovido por la modernidad.

do para establecer una alianza mundial que se comprometa a poner fin a la discriminación contra niños y adolescentes con el propósito de persuadir a los dirigentes de que actúen en favor de los niños, inspirar e involucrar a la población mundial en los asuntos que afectan a los niños y escuchar las opiniones de los propios jóvenes. 
Siglo XXI: hacia la desaparición de la infancia

Uno de los acontecimientos más importantes que tendrán que enfrentar las políticas educativas durante los próximos años tiene que ver con las profundas transformaciones que está sufriendo la concepción de infancia en el mundo occidental. No se trata de un asunto meramente académico e intelectual, por el contrario, ha sido un conjunto de prácticas y condiciones sociales y culturales el que ha venido mostrando los cambios radicales que la sociedad occidental de finales del siglo $X X$ y comienzos del XXI viene consintiendo a propósito de su mirada y sus nuevas formas de tratar a la infancia.

De acuerdo con los análisis del sociólogo norteamericano Neil Postman (1999), la subsistencia de la concepción de infancia moderna dependía de dos principios fundamentales: el control de la información y la secuencia en el aprendizaje. La infancia estaba protegida contra cierto tipo de información, no todo estaba disponible, muchas cosas debían reservarse de la mirada y de los oídos de los niños. De otra parte, la concepción moderna de la infancia (quizás desde Comenio) como una etapa especial de la vida, llevó a pensar en la secuencialidad como principio rector de los procesos educativos y de los aprendizajes: la infancia procede de lo simple a lo complejo, de lo fácil a lo difícil, de lo particular a lo general. La educación es una secuencia, el aprendizaje requiere una graduación, una estructura jerárquica.

Ahora bien, estos dos principios han sido horadados por las recomposiciones que la comunicación y la información han sufrido en la sociedad a lo largo del siglo XX. El telégrafo inició el proceso que llevaría a la pérdida del control que sobre la información ejercían la escuela y la familia: posteriormente la radio, el cine y la televisión completarían el proceso a través de la alteración del tipo de información a que los niños podían tener acceso, su calidad y cantidad, su secuencia y la circunstancias en que sería vivida. (POSTMAN, 1999: 86) En particular, la expansión social de la televisión es el acontecimiento que más ha contribuido a la destrucción de la línea divisoria que la sociedad occidental había trazado entre infancia y edad adulta, en tres sentidos: en primer lugar, porque no requiere entrenamiento particular para asimilar su funcionamiento -a diferencia de lo que acontece con el libro cuyo acceso implica un complejo proceso de asimilación de reglas y un aparato lógico particular-; en segundo lugar, porque no hace exigencias complejas ni a la mente, ni al comportamiento; por último, porque no discrimina su público -el lenguaje de la imagen va dirigido a todos, no es exclusivo, no requiere un abecé. (POSTMAN, 1999: 92).

De acuerdo con Postman, la sociedad contemporánea está mostrando, a través de distintas prácticas, la desaparición de esa línea que la modernidad dibujó para identificar la infancia como una etapa claramente diferente al adulto:

- Tomando como punto de referencia el año de 1900, se puede mostrar que el inicio de la pubertad se ha venido adelantando a un ritmo de 4 meses por década; es decir, mientras en 1900 la primera menstruación era aproximadamente a los 14 años, en 1979 la edad promedio eran los 12 años.

- En la televisión, niños y niñas son mostrados y representados como adultos en miniatura, proceso que podría denominarse como la "adultificación" de la infancia. En este sentido, pareciera que estuviésemos retornando a la Edad Media en donde esa era la concepción predominante de la infancia, según nos lo relata Philippe Ariès.

- A medida que el concepto de infancia se hace más difuso, los indicadores simbólicos de la infancia se difuminan con él. Varios ejemplos ilustran esta situación: ya no existe hoy un traje particular que diferencie a la infancia; las prácticas alimenticias han venido borrando las diferencias entre los hábitos de niños y adultos (pizza, hamburguesa, emparedados, bebidas gaseosas, etc., forman parte de la dieta normal de millones de niños y adultos en el mundo).

- Los juegos infantiles están desapareciendo, a cambio, cada vez más los deportes profesionales se constituyen en los juegos comunes de niños y adultos (fútbol, basketbol, beisbol).

- Aquello que divierte a los niños también divierte al adulto; el cine comercial produce gran cantidad de películas en donde el carácter de "apta para menores" en ningún momento excluye el disfrute de los adultos.

- Hoy no podría decirse que existe una música particular que identifica a la niñez; tanto niños como jóvenes y adultos pueden compartir gustos musicales comunes que encuentran a disposición en las emisiones radiales aptas para todos.

- El dominio de los adultos sobre el lenguaje no es, en la mayoría de los casos, mucho mayor que el de los niños. En la televisión, en la calle, en la radio, en el cine, en las transacciones comerciales, incluso en el aula de clase, no se nota que los adultos usen un lenguaje con más variedad, profundidad y precisión que los niños.

- Existe hoy una acelerada disminución de la diferencia entre las tasas de criminalidad de adultos y niños y que se explica por el asombroso aumento de la criminalidad infantil. (Niños de diez a trece años de edad aparecen involucrados en crímenes de adultos como nunca antes). 
- El nivel elevado de actividad sexual entre adolescentes desde los años sesenta del siglo XX, está mostrando que el oscuro y profundo misterio adulto del sexo se está transformando en producto disponible para todos. (POSTMAN, 1999: 142-151).

Si bien Postman nos habla de la sociedad norteamericana de la década de los años ochenta, más recientemente Mariano Narodowski (1999) -investigador Argentino- considera que la sociedad del siglo XXI ha entrado, definitivamente, en un proceso de "desinfantilización", para lo cual señala dos rasgos particulares: la infancia hiperrealizada y la infancia desrealizada. En el primer caso, se trata de la infancia de la realidad virtual, "de los chicos que realizan su infancia con Internet, computadoras, sesenta y cinco canales de cable, vídeo, family games, y que hace ya mucho tiempo dejaron de ocupar el lugar del no saber. Suelen ser considerados como 'pequeños monstruos' por sus padres y sus maestros y parecen no generar cariño o ternura o, al menos, no ese cariño o esa ternura que guardábamos tradicionalmente para la infancia moderna. No suscitan en sus adultos 'protectores' demasiada necesidad de protección" (NARODOWSKI, 1999: 47).

En el segundo caso, se trata de la infancia de la calle, de la infancia abandonada, de aquella infancia que es independiente, que es autónoma porque vive en la calle, porque trabaja desde muy temprana edad. "Son también los chicos y las chicas de la noche, que pudieron reconstruir una serie de códigos que les brindan cierta autonomía económica y cultural y les permiten realizarse, mejor dicho, des-realizarse, ésa es la palabra correcta, como infancia. Son niños hacia los cuales difícilmente tendremos un sentimiento moderno de infancia, ternura y protección. Hay una niñez que no está infantilizada, una niñez que no es obediente -porque no precisa obedecer, en muchos casos-, una niñez que no es dependiente -es independiente en la negociación cotidiana para lograr su sustento-y, por tanto, una niñez que es autónoma -y que en la calle construye sus propias categorías morales-. Una niñez que, al verla sola o en grupo, difícilmente nos causa ternura" (NARODOWSKI, 1999: 51).

Trátese de la desaparición de la infancia, de la desinfantilización o de la adultificación de la infancia, de cualquier manera las prácticas culturales contemporáneas están dibujando (o desdibujando) un nuevo rostro para aquello que llamábamos la infancia o la niñez. Como en el Antiguo Régimen, en la sociedad contemporánea viviremos adultos infantilizados y niños adultificados; la oferta cultural de los mass media, en particular de la televisión, y las tecnologías de la información y la comunicación, en particular Internet, nos obligan a preguntarnos hoy: ¿A quiénes pretendemos educar? ¿Desde qué instituciones y procesos pretendemos hacerlo? ¿Desde qué principios y con cuáles herramientas pretendemos hacerlo? Las anteriores líneas son una primera aproximación a un tema de investigación que recién comienza. Por lo pronto, como resulta evidente, seguimos empeñados en una concepción de infancia que se estrella cada vez de manera más fuerte con esas nuevas subjetividades que habitan nuestros "jardines", escuelas y colegios.

\section{ALGUNAS REFLEXIONES FINALES}

\section{La juventud en la mira}

La desaparición de la infancia implicará grandes transformaciones dentro del saber pedagógico, de ahí la necesidad de abordar a fondo el problema de los sujetos y los procesos de subjetivación en la modernidad. Ahora bien, si la infancia parece estar desapareciendo, la juventud aparece hoy en el centro de las preocupaciones; podríamos decir que si el siglo XX fue el siglo del niño, el siglo XXI será el siglo de la juventud. Desde hace algunos años hemos venido escuchando un rumor de voces que desde distintos ángulos vienen planteando su preocupación por los jóvenes y adolescentes. De la misma manera, acciones oficiales y privadas, programas sociales, agendas educativas de instituciones internacionales y políticas estatales han venido interviniendo sobre este importante sector de la sociedad.

Paralelamente a este conjunto de discursos y prácticas, una forma particular de representarnos la juventud ha venido ganando terreno en el imaginario social: las imágenes construidas en torno a los jóvenes de los barrios periféricos de las grandes ciudades, nos muestran una sociedad que sospecha de las actitudes, sentimientos y capacidades de sus jóvenes, una sociedad en donde la juventud es vista como delincuencia potencial y como sinónimo de descomposición social.

Por otro lado, los nuevos procesos económicos que vive la sociedad contemporánea han generado un interés inusitado por los jóvenes identificándolos como una masa significativa de consumidores y por tanto gran parte de las estrategias comerciales se dirigen hoy hacia la captura de ese mercado. De esta forma, paralelamente a la venta de una amplísima gama de objetos materiales para el consumo, ha venido consolidándose la industria igualmente lucrativa de la venta de imágenes, símbolos y valores.

El consumo simbólico, característica de las sociedades contemporáneas, ha encontrado en la juventud (y en la infancia) un espacio sui generis para ampliar su mercado, y en los medios de comunicación sus mejores aliados ${ }^{3}$. Así, mientras para un sector considerable de la socie-

\footnotetext{
${ }^{3}$ Al respecto ver: Steinberg, Shirley R. Cultura infantil y multinacionales. Madrid: Ediciones Morata, 2000.
} 
dad la juventud representa una amenaza latente, para otro significa una posibilidad sin igual de aumentar ganancias expresadas no sólo en términos económicos sino además ideológicos.

Frente a estos hechos es necesario replantear la concepción de juventud, y con ello, la mirada perversa hacia las actitudes de los jóvenes de hoy. Pero antes que una caracterización o esquematización psicologista, es necesario un análisis en una perspectiva más social y cultural. La juventud no es sólo una etapa psicológica sino un hecho social, cultural e histórico de amplias potencialidades creativas y transformadoras. (Recordemos cómo el movimiento juvenil de los 60 planteó la posibilidad de generar diversos estilos de vida, nuevas prácticas a la vez que incidió en la creación de nuevas formas de pensar cuyos ecos llegaron incluso a tocar las reflexiones filosóficas del momento). Como se aprecia, es este un problema central que deberá asumir la reflexión pedagógica y que toca directamente con el quehacer de los nuevos educadores.

\section{¿Maestro o pedagogo?}

El panorama contemporáneo ha puesto de presente la crisis de la figura social y profesional del maestro. Para Tedesco, la pérdida de capacidad socializadora de la escuela a causa de la masificación de la educación, la pérdida de prestigio de los maestros, la rigidez de la institución educativa y de los sistemas educativos, el auge de los medios de comunicación, expresan el significativo deterioro del maestro como agente socializador. $Y$ así como la televisión ha llevado a la desaparición entre la niñez y la adultez, "en la escuela se produjo un proceso de desaparición de las distinciones entre maestro y alumno", hecho que tiene que ver, principalmente, con la crisis de la autoridad en la sociedad contemporánea. Según Tedesco estaríamos ante la "desaparición del maestro", hecho que más allá de las polémicas que pueda generar, constituye una afirmación que vale la pena profundizar y ante la cual el nuevo educador que se quiere formar tendrá que tomar posición.

La importancia que ha tenido el maestro en nuestra cultura ha estado definida por los alcances sociales de la escuela, escenario privilegiado del ejercicio docente. Hoy la escuela ha perdido su papel protagónico en los procesos de producción y reproducción cultural, y por tanto la función y rol del maestro se ha visto limitada y cada vez más distante de los procesos y la dinámica de producción de saber sobre la educación y la pedagogía. Estos hechos, a la vez que ratifican la condición de subordinación intelectual del maestro, condición histórica que lo ha acompañado desde su aparición en nuestro territorio, ponen de presente la aparición de una multiplicidad de nuevos sujetos que cumplen funciones pedagógicas de gran importancia social.

Por estas razones, es necesario dejar un poco al lado la preocupación por el maestro y la escuela y enfatizar la mirada en los nuevos sujetos (educadores comunitarios, grupos de acción social, locutores, periodistas, actores, personajes cinematográficos, cantantes, artistas, etc.) y escenarios pedagógicos (medios de comunicación, parques, ciclovías, calles, centros comerciales, en fin, la ciudad). En una sociedad en donde la comunicación y el manejo de la información es cada vez más importante, la formación adquiere un nuevo sentido y las apuestas por la educación pública tienen que pasar necesariamente por la discusión sobre el problema de la distribución del conocimiento y el manejo, procesamiento y acumulación de información. De otro lado, la complejidad simbólica de la vida contemporánea impone a los sujetos el desarrollo de nuevas competencias frente a las cuales la escuela y el maestro permanecen ajenos.
La vida cotidiana ha venido sufriendo un proceso de "pedagogización" y por tanto de control simbólico, de ahí que pensar hoy el problema de la democracia pasa por la construcción de discursos y prácticas de resistencia frente a la imposición de códigos hegemónicos y a favor de la diversidad de interpretaciones y usos de la oferta simbólica y cultural. Y esta, desde luego, es una lucha que va más allá de las fronteras de la escuela y del alcance del maestro tradicional.

\section{Bibliografía}

BADINTER, Elisabeth (1991) ¿Existe el instinto maternal? Historia del amor maternal. Siglos XVII al XX. Barcelona: Paidós.

CONVENCIÓN SOBRE LOS DERECHOS DEL NIÑO. (1989).

\section{DECLARACIÓNDE GINEBRA. (1924).}

DECLARACIÓN UNIVERSAL DE LOSDERECHOS DEL NIÑO. (20 de noviembre de 1959).

MOVIMIENTO A FAVOR DE LA INFANCIA. Web.

Muel, Francine. (1991) "La escuela obligatoria y la invención de la infancia anormal". En: Espacios de Poder. № 6, pp. 123-142. (Madrid. La Piqueta).

NARODowski, Mariano. (1999) Después de clase. Desencantos y desafíos de la escuela actual. Buenos Aires: Ediciones Novedades Educativas.

Postman, Neil: (1999) "O desaparecimento da infância”(Rio de Janeiro, Graphia).

SÁEnz Obregón, Javier; Saldarriaga, Óscar y OsPINA, Armando (1997) Mirar la Infancia: Pedagogía moral y modernidad en Colombia, 1903-1946. (Colombia. Universidad de Antioquia).

SALDARRIAGA, Óscar. (2000) Matrices éticas y tecnologías de formación de la subjetividad en la pedagogía colombiana, siglo XIX y XX. Revista Pretextos pedagógicos № 9, pp.19-51 (Bogotá. Sociedad Colombiana de Pedagogía-Socolpe). 